\title{
Bridge flap reconstruction of the lower eyelid
}

\author{
F. P. ENGLISH AND N. D. McDERMOTT
}

Department of Ophthalmology, Mater Hospital, University of Queensland, Australia

Although numerous conditions may result in loss of eyelid tissue, the aetiological agent generally concerned is one of trauma, tumour, or congenital anomaly. Ideally, wherever possible, this is rectified by primary anastomosis with or without cantholysis. However, in the face of a large deficit, other techniques are employed (Smith, I959; Mustardé, I 966; Smith and English, I970).

In such circumstances a conventional manner of restoration of the lower eyelid is the tarso-conjunctival slide operation (Fig. I) perfected by Hughes (1954). The anatomical limitation of the lower eyelid which has a narrow tarsus precludes this manoeuvre for reconstruction of the upper eyelid. In America Cutler and Beard (1955) have devised an ingenious bridge flap technique.

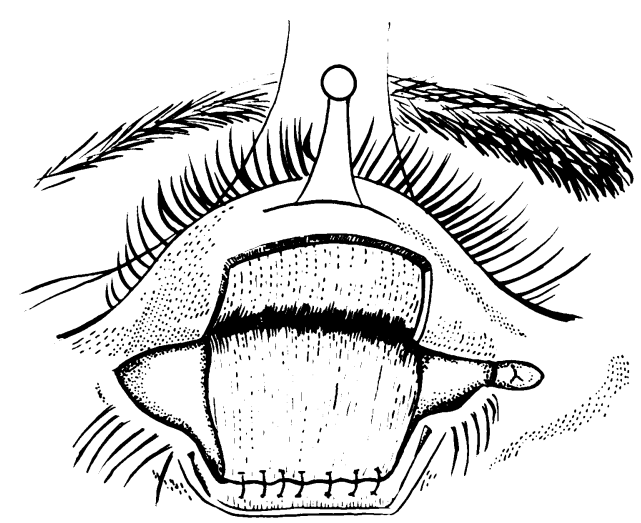

FIG. I. Key diagram to tarso-conjunctival slide operation, a conventional way of reconstructing the lower eyelid

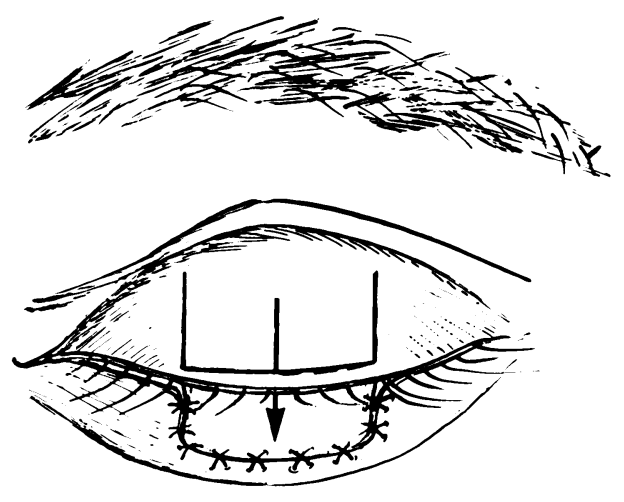

FIG. 2. Diagram of bridge flap technique of reconstruction of the lower lid

Recently Hecht (1970) in Boston has broken away from the traditional approach to lower eyelid repair and has obtained good results with a reversed Cutler-Beard operation. In his technique a flap is prepared above the upper lid fold so that little or none of the tarsus is incorporated in the section.

Concerned about the possibility of damage to the levator palpebrae superioris with such a high incision, we have devised a similar more direct approach to this problem using the bridge flap principle (Fig. 2). 


\section{Surgical procedure}

When a tumour is concerned (Fig. 3), 4-o silk stay sutures are inserted in healthy adjoining tissue and traction applied to the eyelid. The vertical section is initiated with a razor blade knife introduced from the direction of the conjunctival cul-de-sac. This avoids the shearing of the wound edges which is sometimes seen with a scissors section. Excision of the lesion is completed with a horizontal incision.

Now an Erhardt clamp is applied to the upper eyelid and the proposed flap is outlined with surgical ink (Fig. 4). The lower border is located $3 \mathrm{~mm}$. above and parallel to the lid margin, thus preserving the integrity of the important marginal arterial arcade.

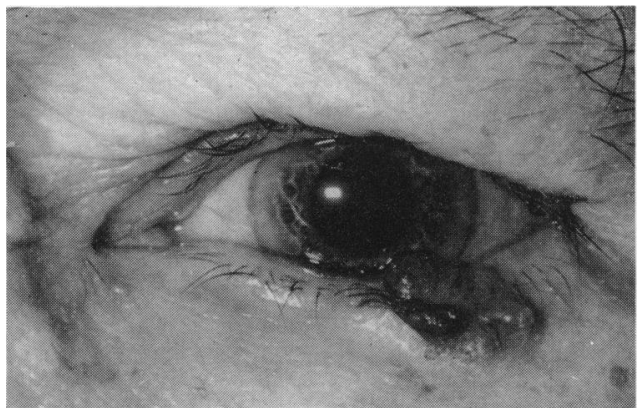

FIG. 3. Preoperative photograph of basal cell carcinoma of lower lid

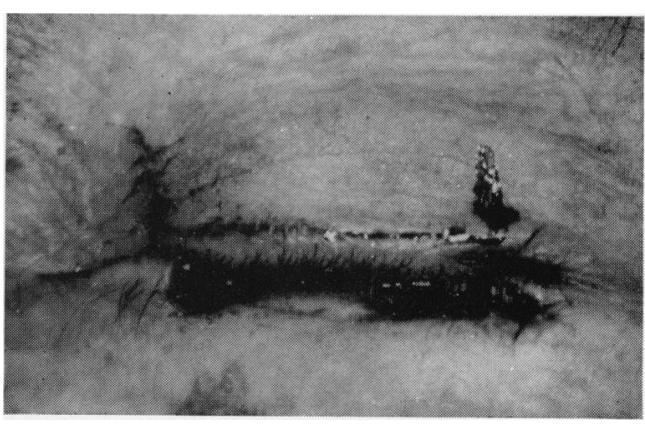

FIG. 4. Outlining the flap on the upper eyelid with surgical ink

At this stage a full-thickness incision is performed with a Bard Parker knife and the straighen vertical margins are completed with scissors. It is important to have the horizontal dimension slightly less than that of the deficit, otherwise a sagging patulous lower eyelid will result.

This tongue of tissue is then passed under the bridge constituted by the lid margin and positioned snugly into the recipient bed (Fig. 5). Any alteration to the extent of advancement is made at this stage. Buried subcuticular sutures are used and the skin incision is closed with interrupted fine silk sutures. There is no need to suture the superior border of the bridge which rapidly becomes epithelialized. Attempts at suturing could in fact embarrass the circulation of the vital lid margin. A Telfa dressing is placed on the wound and a light pressure pad applied.

With the passage of time the flap will be found to elongate, so that it is practically doubled after 6 weeks. At this time the blepharorrhaphy is opened with straight Stevens scissors (Fig. 6), and the

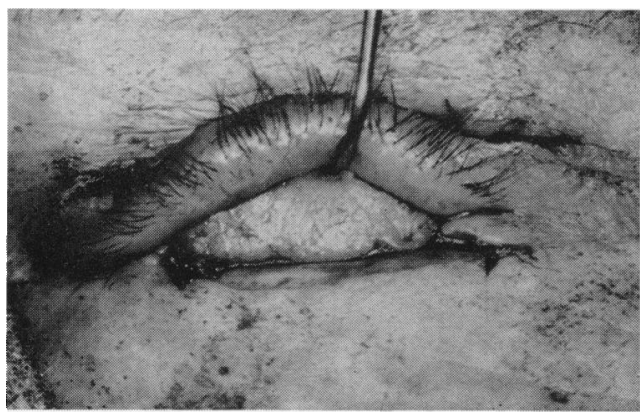

FIG. 5. Passing the flap under the bridge of the intact eyelidmargin and placing it in position in the recipient bed

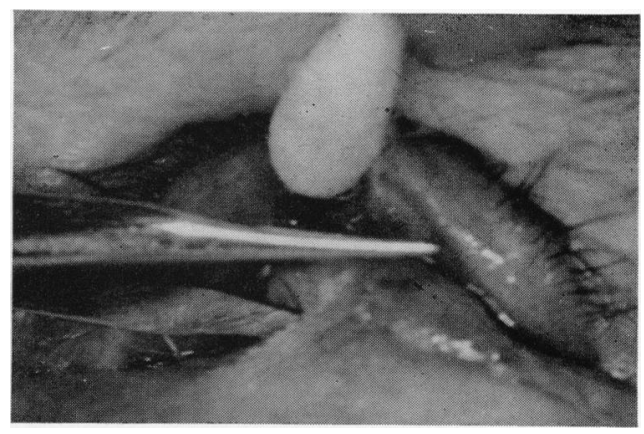

FIG. 6. Opening the blepharorrhaphy with scissors 
new lid is trimmed into perspective. The flap is now taken back under the original bridge and sutured into its proper position in the upper eyelid (Fig. 7). At a later stage a cilia graft can be performed if desired.

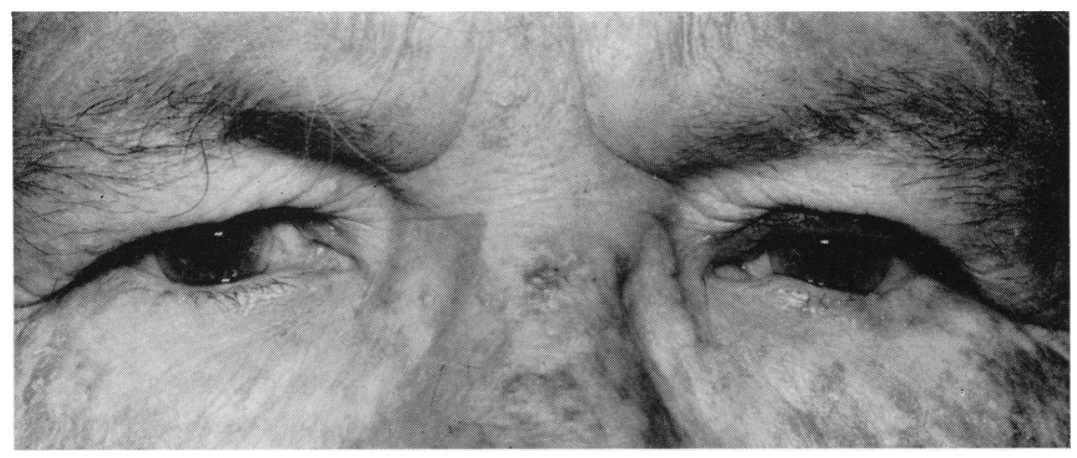

FIG. 7

Appearance 6 weeks after operation

\section{Conclusion}

This technique offers a simple and expedient way of reconstructing the lower eyelid. It has advantages over the tarso-conjunctival slide manoeuvre, in that it involves fewer stages. Furthermore, it avoids the complication of the thickened boggy eyelid, which sometimes occurs when the overlying skin graft has not been meticulously prepared.

The diagrams are by courtesy of Mr. Warren Keats of the C.S.I.R.O., Brisbane

\section{References}

GUTLER, N. L., and BEARD, C. (1955) Amer. F. Ophthal., 39, I HECHT, s. D. (1970) Arch. Ophthal. (Chicago), 84, 760

HUGHeS, w. L. (1954) "Reconstructive Surgery of the Eyelids", 2nd ed., p. I85. Mosby, St. Louis MUSTARDÉ, J. E. (1966) "Repair and Reconstruction in the Orbital Region", p. i 16. Livingstone, Edinburgh

smith, в. (1959) Surg. Clin. N. Amer., 39, 367 and ENGLish, F. P. (1970) Brit. F. Ophthal., 54, 450 